\title{
Corrigendum: Fas ligand-mediated paracrine T cell regulation by the receptor NKG2D in tumor immunity
}

Veronika Groh, Kimberly Smythe, Zhengpeng Dai \& Thomas Spies

Nature Immunology 7, 755-762 (2006); published online 28 May 2006; corrected after print 20 June 2006

In the version of this article initially published, the key and figure labels for Figure 8c are incorrect. The gray bars are C1R-A2-MICA-M27, the filled bars are C1R-A2-M27, and the cells are $\mathrm{CD}^{+}\left(\right.$not $\left.\mathrm{CD}^{+}\right)$. The error has been corrected in the HTML and PDF versions of the article.

\section{Corrigendum: B cell development and immunoglobulin gene transcription in the absence of Oct-2 and OBF-1}

Karin Schubart, Steffen Massa, Daniel Schubart, Lynn M. Corcoran, Antonius G. Rolink \& Patrick Matthias

Nature Immunology 2, 69-74 (2001); published online January 2001; corrected after print 10 August 2006

In the version of this article initially published, the Oct- $2^{-1-}$ plot in the second row of Figure 1a is incorrect. The correct plot is provided. The error has been corrected in the HTML and PDF versions of the article.
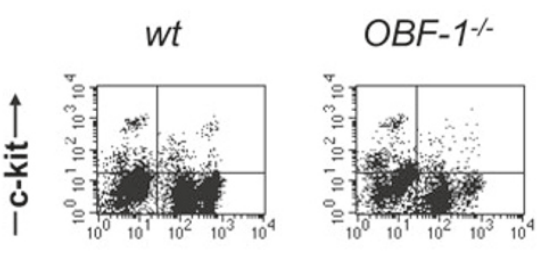

Oct-2-/

OBF-1\%Oct-2-1-
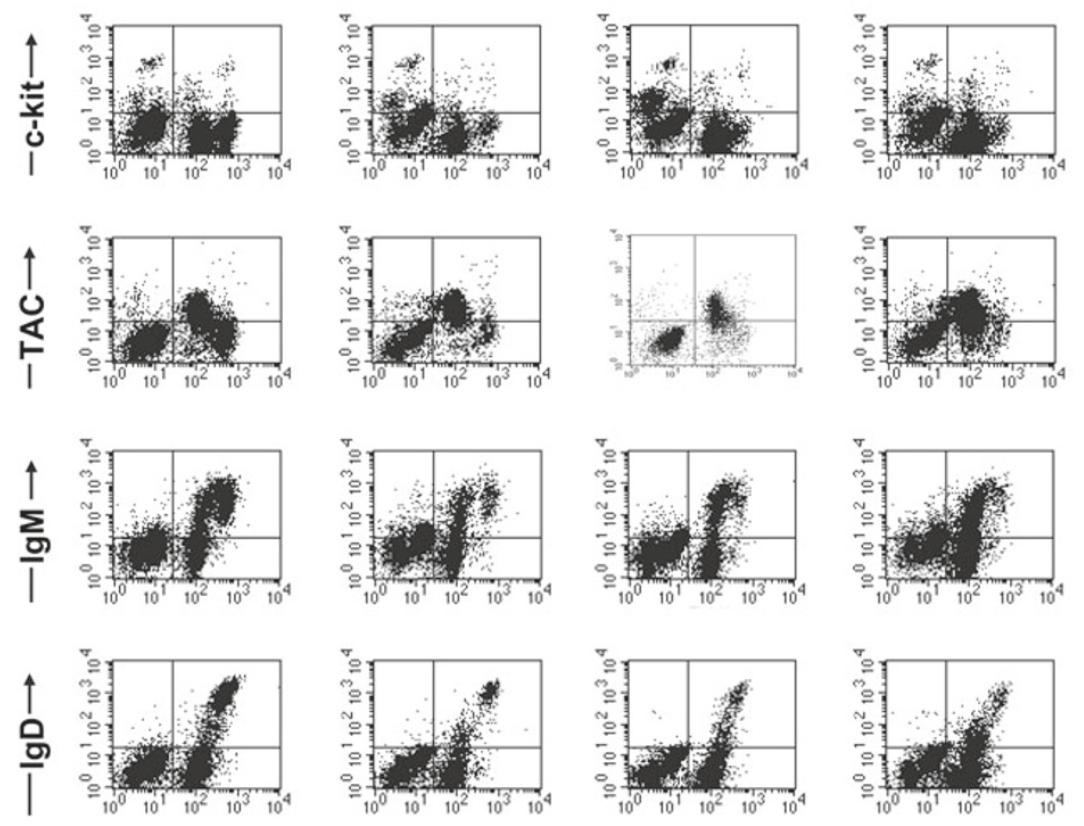

- B220 $\longrightarrow$ 